\title{
RIESGO OPERATIVO EN EIFS BOLIVIANAS POR CONDUCTAS IMPROCEDENTES DE PROFESIONALES FORMADOS EN UNIVERSIDADES BOLIVIANAS
}

\section{Marcos Alfredo Alfonso Pereira Delgadillo}

\section{RESUMEN}

Un sistema financiero sólido, está sustentado por Entidades de Intermediación Financiera (EIFs), con profesionales cualificados que además deben contar con alta formación de valores. Sin embargo, se observa excesos cometidos por funcionarios de EIFs, debido entre otros aspectos, a la ausencia de ética y valores en el desempeño de sus funciones, sin ser la excepción las EIFs de Bolivia, existiendo alto "Riesgo Operativo", de que estudiantes de universidades bolivianas que desean trabajar en EIFs incurran en similar situación. Este artículo propone un modelo conceptual con una serie de proposiciones teóricas que sugieren: a) que si un empleado de una EIF no ha recibido durante su proceso de formación universitaria, educación en valores, podría tener comportamientos improcedentes que generen eventos de riesgo operativo y consecuentemente pérdidas a EIFs bolivianas; b) que con un adecuado proceso de selección de personal, que incorpore test psicotécnicos en valores, se podría reducir el comportamiento improcedente y la probabilidad de eventos de riesgo operativo en el sistema de intermediación financiero y; c) que funcionarios de EIFs cuyos comportamientos éticos reflejan ciertos valores, tendrían menos comportamientos improcedentes.

Palabras Clave: Enseñanza de Ética y Valores en Universidades, Procesos de Selección de Personal, Gastos Indeseados en Cuentas Contables, Conductas No Éticas, Riesgo Operativo EIFS Bolivianas.

DOI: 10.23881/idupbo.021.2-4e 